IFN Working Paper No. 887, 2011

\title{
Intelligence, Self-confidence and Entrepreneurship
}

Andrea Asoni 


\title{
Intelligence, Self-confidence and Entrepreneurship
}

\author{
Andrea Asoni \\ University of Chicago and \\ Research Institute of Industrial Economics (IFN)
}

October 22, 2011

\begin{abstract}
I investigate the effect of human capital on entrepreneurship using the National Longitudinal Survey of Youth - 1979. I find that individuals with higher measured intelligence and self-confidence are more likely to be entrepreneurs. Furthermore I present evidence suggesting that intelligence and self-confidence affect business ownership through two different channels: intelligence increases business survival while self-confidence increases business creation. Finally, once we control for intelligence and self-confidence the effect of formal college education almost completely vanishes. These results are robust to controlling for selection into entrepreneurship and selection into college.
\end{abstract}

Key words: Entrepreneurship, College Education, Intelligence, Self-confidence JEL classification: C41, J24, L26 


\section{Introduction}

Bill Gates and Steve Jobs never completed their college studies but started two of the most successful and famous firms in the world. Gordon Moore instead earned a Ph.D. from Caltech before going on to found Intel Corporation. The weak link between education and entrepreneurship suggested by these anecdotes is confirmed by empirical research on the determinants of entrepreneurship which does not find conclusive evidence on the effect of education on business ownership (Van der Sluis et al. 2008 provide a review of the recent literature).

Are there other human capital factors that explain successful entrepreneurship? Recent articles have emphasized the effect of cognitive and non-cognitive skills, such as intelligence and self-confidence, on socio-economic success, from labor market outcomes (Heckman et al. 2006), to criminal behavior (Heckman et al. 2011), to health and longevity (Savelyev 2011).

In this article I investigate the effect of cognitive and non-cognitive skills on business dynamics. I show that intelligence and self-confidence have a positive effect on the rate of entrepreneurship and that this effect is robust across different specifications. I also present evidence suggesting that intelligence and self-confidence raise the rate of entrepreneurship through two different mechanisms: smarter people are less likely to become entrepreneurs but more likely to stay in business once they enter; more self-confident people, instead, are both more likely to enter and more likely to stay in business. The effect of self-confidence on entry and intelligence on survival are robust to controlling for selection into entrepreneurship and selection into college. Lastly, when we control for intelligence and self-confidence, college education has a weak or no effect on business dynamics.

I use data from the National Longitudinal Survey of Youth - 1979 (NLSY79), a longitudinal survey covering about 13,000 individuals started in 1979 and still ongoing. This rich dataset includes many demographic variables, such as race, gender and education, a detailed working history and 
useful measures of cognitive and non-cognitive abilities. Due to the possible endogenous nature of both education and occupation I employ an empirical approach that takes these sources of bias into account. Within this framework it is also possible to distinguish those who quit their job to start a business venture from those who were not employed at the time they started a firm, and to analyze separately the effect of human capital on incorporated and unincorporated businesses.

Next section illustrates the data used in this paper. The third section reports the main results and the fourth concludes.

\section{Data}

I construct a unique dataset combining data from two different sources: the National Longitudinal Survey of Youth - 1979 (NLSY79) and the National Center for Education Statistics. The first is a longitudinal survey collected by the Bureau of Labor Statistics, that contains detailed demographic and employment information regarding a representative sample of the U.S. population. From the website of the National Center of Education Statistics I downloaded a list of all 4-years American colleges, complete with a detailed description of each institution.

Let me briefly describe these two sets of data.

\subsection{The National Longitudinal Survey of Youth}

The NLSY79 spans more than 30 years and covers 12,686 individuals who were between 14 and 22 years of age in 1979. The members of the sample were interviewed yearly until 1994 and every two years after that.

This dataset has a few advantages. First, its longitudinal nature coupled with detailed information on employment. This allows us to reconstruct every individual's entire employment history, 
i.e. the succession of employment or non-employment spells. In particular, we observe each entrepreneur both before he decides to start a firm and after he leaves it. This information can be used to identify individual specific unobserved factors.

The second advantage of the NLSY79 is that it contains a rich set of demographic, financial and macroeconomic variables, among them measures of intelligence and self-confidence.

Preliminary analysis (Table 1) shows that while men and women are similar along many dimensions, such as the share of the population with a college degree, they are different when it comes to business ownership patterns. Women are at any time less likely to own a business and the fraction that reports on ever owning a business is lower. Moreover the variable of interest, college education, has different effects for the two genders ${ }^{1}$. This evidence, together with similar findings in the labor literature (Macpherson, 1988; Simpson and Sproule, 1998) suggests that we need to study the effect of human capital on entrepreneurial dynamics separately for men and women. I leave to a future article the analysis of women's entrepreneurial patterns and focus in this article on men.

Men represent half of the surveyed individuals (50.4\%); in 1980 there are approximately 6,000 young men in the sample (Table 2), almost half of which is in school. Not a surprising fact given that they are between 15-22 years of age. Predictably, as the population ages, the share of students declines to less than $1 \%$ and the share of individuals with a college degree increases to around $25 \%$ twenty-four years later. The employment rate increases over time, as people leave school, and in 2004 is comparable to the national average for an adult population.

Table 2 also suggests that some attrition exists: the sample size decreases by about a third over the entire period. Mortality rate for a comparable cohort in the general population is around $4 \%^{2}$. Despite the high rate of attrition, table 3 does not show a strong survivorship bias. While the percentage of minorities is slightly increasing, the average levels of intelligence and self-confidence 
do not change dramatically over time.

\subsection{Human Capital Measures}

I focus on the effect of human capital on entrepreneurship; let me carefully define both, starting with human capital. I use three measures of human capital: college education, intelligence and self-confidence. The first is a dummy variable equal to one if the individual has a 4-years college degree. The share of the adult population reporting a 4-years college degree is around $25 \%$, which is in line with the national average. Notice that with this measure I leave out of the educated group college drop-outs and two-years degrees.

Intelligence is measured at the time the survey was initiated. All the individuals in the NSLY79 took a test similar to the Armed Forces Qualification Test (AFQT), an achievement test that the American army has been using since 1950 to select its recruits. While there are other non-cognitive abilities that influence the results of such test, it is nevertheless highly correlated with general intelligence and can be considered a reliable measure of the general intelligence factor (Heckman and Rubinstein, 2001). While there is a relationship between age and score on the AFQT, in the regressions I control for age and I repeat the analysis with an age-adjusted version of the AFQT which does not change the results.

Self-confidence is also measured in 1979 and is evaluated through an assessment of people's locus of control. Rotter (1966) proposed a psychological test evaluating the extent to which someone believes to be in control of the events that affect his life. Scores on such test in the NLSY79 are between four and sixteen; a lower score corresponds to a more "internal locus of control", or a stronger belief that our own actions will determine what happens in our lives.

I need to point out that locus of control is not a perfect measure of self-confidence but captures a host of non-cognitive abilities, such as "cognitive processing, autonomy, resistance to influence 
attempts, delay of gratification and self-confidence" (Duttweiler, 1984). Moreover there are some aspects of what is commonly considered self-confidence, such as the belief to be able to carry on the actions necessary to achieve one's goal (self-efficacy) ${ }^{3}$, that are not captured by the locus of control (Bandura, 1977). Nevertheless, locus of control strongly correlates with confidence and can safely be used as a measure of it (Lefcourt, 1976; De Brabander et al. 1999).

\subsection{Business Ownership in the NLSY79}

The NSLY79 has a weekly measure of employment status. For every week of the year the respondent is asked to report his main activity. I classify people into three mutually exclusive categories: employed, non-employed and self-employed ${ }^{4}$. Employed individuals are those who are working for someone else; non-employed are both unemployed and out of the labor force and self-employed are those who report to work in their own business. Furthermore self-employed individuals are asked whether they have an incorporated or an unincorporated business. Incorporated businesses are defined as those taxable entities that need a charter to be established, respect State and Federal regulations and act as individuals through their officers with by-laws and stock privately or publicly held; unincorporated businesses are sole-proprietorship or partnership that only need a business license to operate.

\subsection{College Data}

The NLSY79 does not provide a measure of distance from college. Closeness to college is an important exogenous determinant of the probability of going to college, as it will be explained in detail in the next section. In order to build such measure I downloaded from the National Center for Education Statistics (NCES) the list of American four-years colleges, together with some information regarding these institutions. There are 2,966 colleges in the United States; for each college I collected 
information on its legal status (public or private), its geographical location, number of graduate and undergraduate students, and other characteristics. The geographical location of each college is particularly useful because it allows me to calculate the distance between each individual and the closest college at time of high school graduation, which I use as an instrument for college attendance.

\section{Intelligence, Self-confidence and Entrepreneurship}

\subsection{Human Capital and the Rate of Entrepreneurship}

Intelligence and self-confidence are positively related to entrepreneurship rate (table 4, first column). In particular those who display more self-confidence have the highest entrepreneurship rate, about two percentage points higher than the population rate and almost four percentage points higher than those who exhibit the least self-confidence. Similarly, those who score high on the intelligence test report an entrepreneurship rate that is two and a half percentages points higher than those who score among the lowest on the AFQT. On the other hand having a college degree does not seem to have a positive impact on the entrepreneurship rate. The rate of business ownership among college educated is slightly lower than among those without a college degree and lower than the average. These differences however are small, all within a single percentage point, so that the effect of college education does not seem very strong.

The relationship between cognitive, non-cognitive abilities and entrepreneurship holds also when controlling for education, as illustrated in table 5. It shows the entrepreneurship rate for high and low intelligence and high and low confidence individuals among those with a college degree and those without. As before the most confident people are those with the highest entrepreneurship rate. Similarly smarter people have higher entrepreneurship rate than those with lower scores on the AFQT. Finally, by looking at entrepreneurship rate along the same row we notice again that 
college education seems to have a negative effect on entrepreneurship.

Self-confidence has a strong effect on entrepreneurship even controlling for cognitive skills, while the effect of general intelligence is not as pronounced when controlling for self-confidence. As seen in table 6 high confidence people have a higher entrepreneurship rate both among the smartest people and the least smart, but the usually positive effect of intelligence is reversed among the low confidence individuals.

The probit analysis presented in table 7 shows the effect of each human capital factor holding the others constant and controlling for a host of demographic and macroeconomic variables. The intuition provided by the tables above is confirmed: the effect of having a college degree on entrepreneurship rate is negative or not significant, while the effects of intelligence and self-confidence are always positive and statistically significant.

These results generally hold also when separating incorporated from unincorporated businesses. The distinction is not merely a matter of legal status but seems to be related with the underlying economic charatecteristics of the firms. Incorporated businesses seems to be more successful along important measures such as size, income generated and survival rate. Table 8 shows the effect of human capital on the likelihood of owning an incorporated or an unincorporated business. It seems that the effect of college depends on the type of business considered. While very weak in both cases, college increases the probability of having an incorporated business but decreases the likelihood of owning an unincorporated firm. This could be related with the fact that while most of the unincorporated firms are in the manifacturing, retail and construction industries, most of the incorporated ones are in the business and professional service industries. While college is not required to run a construction company, it is necessary to run a law firm. The effect of intelligence and self-confidence instead is unchanged: they are both positively related with business ownership, 
irrespectively of the type of business considered.

A clear picture emerges from the previous tables: while the effect of college education is weak and depends on the specification considered, intelligence and self-confidence have a robust positive effect on the rate of entrepreneurship. Next section will argue that intelligence and self-confidence raise the entrepreneurship rate through two different mechanisms.

\subsection{Intelligence, Self-confidence, Business Creation and Business Sur- vival}

Cognitive and non-cognitive skills can cause a higher entrepreneurship rate through higher business survival rates, higher firm creation rates or any combination of the two. This section will show that intelligence and self-confidence increase the rate of entrepreneurship through two different channels. While smarter people are less likely to become entrepreneurs, they are more likely to stay in business conditional on entry. The latter result is more robust. The combination of a seemingly lower entry rate and a higher survival rate on average increases the stock of entrepreneurs among the smartest individuals. Self-confidence instead is associated with a higher entry rate into entrepreneurship and, weakly, with a higher survival rate. This necessarily leads to a higher rate of entrepreneurship among the most confident individuals.

These results are derived from a competing risks occupational model of entry into and exit from entrepreneurship. It is important to point out that a superficial look at the data would produce a different picture. Intelligence and self-confidence are associated with higher survival rates, both in the general population of firms and across incorporated and unincorporated firms (table 10) and they seem to be associated with higher entry rates as well (table 9). While the first result is confirmed by the more careful empirical analysis carried on in this section, the second is not. In 
particular I will show that intelligence is related to a lower propensity to start a business.

To study entry and exit rates I employ a competing risks model of occupational choice. At any given time each individual is in one of three mutually exclusive states, non-employment, employment and entrepreneurship, and with a certain probability he will leave his current state and move to another one. I study the effect of intelligence and self-confidence on the probability of entering entrepreneurship from either employment or non-employment and on the probability of leaving entrepreneurship and moving to one of the other two states.

The main advantage of this framework is that it allows us to take into account the three main sources of bias in our estimates: duration dependence bias, selection into entrepreneurship and selection into college. The first problem, duration dependence bias, is addressed along the lines suggested by the literature in labor economics by assuming a parametric form for the unobserved heterogeneity and integrating out the "average" survival function (e.g. Mealli and Pudney, 1996).

By selection into entrepreneurship I refer to the effect that human capital has on the decision to start a firm. The risk is that there is a relationship, induced by human capital, between the unobservable characteristics of the individuals and their occupation, namely whether they are entrepreneurs or not. If that was the case estimates of the effect of human capital on business survival are unreliable. To address this problem I follow the approach presented in Ham and Lalonde (1996). Their idea is that we can learn something about entrepreneurs' hidden types by including in our analysis their entire employment history, and not only business spells. This additional information is used to estimate the correlation between unobserved types across different spells, entrepreneurial and non-entrepreneurial, induced by human capital therefore measuring the effect of intelligence and self-confidence free of this bias.

Finally to address the problem of selection into college I follow Eberwein et al. (1997) and add to the model a selection equation into college. Two instruments provide the necessary exogenous 
variation: proximity to college interacted with parental education (as in Card, 1995) and deviations from local unemployment rate at high school graduation. Both proximity to college and an unfavorable local labor market situation should raise the probability of going to college, ceteris paribus. The model and the identification strategy are discussed more in details in Asoni (2011).

Table 11 shows the effect of human capital on entry. It looks at both entry from non-employment and entry from employment. Intelligence has a negative effect on entry both from employment and non-employment, although the latter effect seems weak once we control for selection. The coefficients shown in the table imply that a one standard deviation increase in measured intelligence decreases the probability of entry between $19 \%$ and $8 \%$ (on average between non-employed and employed), depending on whether we look at column IV (model with no selection) or V (model with selection). Self-confidence instead has a positive and statistically significant effect on entry, independently of the specification considered. Also the effect is considerably strong: a one standard deviation decrease below the mean in self-confidence decreases the probability of starting a business by about $18 \%$ if we look at the specification that accounts for selection (column V), and by about $24 \%$ in the simpler model (column IV).

Table 12 shows the effect of human capital on business survival. Both intelligence and selfconfidence seems to have a positive effect on survival if we look at exit toward non-employment, although the effect of confidence is measured less precisely. Moreover, an increase of one standard deviation above the mean intelligence implies an increase in average business duration between $26 \%$ and $10 \%$ depending on whether we look at the model that accounts for selection or not; the same increase in self-confidence however only increases survival by $5 \%$ at most. On the other hand if we look at transitions toward employment no human capital variable seems to have a strong effect. This is consistent with the fact that transition toward employment contains different instances. Some people move to employment because they fail as entrepreneurs; others move to employment 
because they have been very successful in managing their firms, for example those whose firms have gone public and are now technically employees of their companies. While in the case of exit toward non-employment we can more confidently equate survival with success ${ }^{5}$ and expect a positive relationship between intelligence, self-confidence and survival, we can hardly do the same with exit to employment.

\section{Conclusions}

The evidence provided in this article suggests that intelligence and self-confidence are important determinants of entrepreneurship. They both increase the probability of owning and managing a firm although they do so through different channels: intelligence increases survival rates of existing firms, while it seems to decrease the probability of starting new companies. Self-confidence on the other hand increases the probability of starting a business and it also has an imprecisely measured, positive effect on business survival. Lastly, formal college education does not seem to play an important role when it comes to entrepreneurship.

These results have implications both for entrepreneurship researchers and policy makers. Empirical researchers should try to include, whenever possible, measures of cognitive and non-cognitive skills in their analysis of entrepreneurship, since my results suggest that they are more important than formal education. Another interesting venue for future research is a better understanding of the role of different aspects of human capital. While the positive relationship between self-confidence and business creation is intuitive, it is less clear its positive link to business survival. Other questions raised by the results above are: why is intelligence negatively related to business creation? Why is intelligence positively related to business survival but college is not? The answer to these questions require a better understanding of the role of human capital in entrepreneurship. 
While this article does not include a formal policy analysis, I believe that these results suggest that a re-evaluation of entrepreneurial policies is needed. Since more innate skills seems to matter more for entrepreneurship, we should consider shifting our pro-business policies from direct support of small businesses to more indirect interventions (Lerner, 2010), geared toward the creation of a more business-friendly economic environment, where the more talented individuals can emerge. 


\section{References}

[1] Asoni, Andrea, "What Drives Entrepreneurship?" Unpublished Manuscript (2011), University of Chicago.

[2] Bandura, Albert, "Social Learning Theory" (Morrinstown, New Jersey: General Learning Press, 1977)

[3] Card, David, "Using geographic variation in college proximity to estimate the return to schooling", in L. N. Christofides, E.. K. Grant and R. Swidinsky (Eds.), Aspects of labour market behaviour: essays in honour of John Vanderkamp (Toronto, Canada: University of Toronto Press, 1995).

[4] De Brabander, Bert, Johan Hellemans and Christophe Boone, "Selection Pressure Induces a Shift Towards More Internal Scores on Rotter's I-E Locus of Control Scale", Current Research in Social Psychology 4:1 (1999), 103-112.

[5] Duttweiler, Patricia C, "The Internal Control Index: a Newly Developed Measure of Locus of Control", Educational and Pschological Measurement 44:2 (1984), 209-221.

[6] Eberwein, Curtis, John C. Ham and Robert J. LaLonde, "The Impact of Being Offered and Receiving Classroom Training on the Employment Histories of Disadvantaged Women: Evidence from Experimental Data", Review of Economic Studies 64:4 (1997), 655-682.

[7] Ham, John C. and Robert J. LaLonde, "The Effect of Sample Selection and Initial Conditions in Duration Models: Evidence from Experimental Data on Training" Econometrica 64:1 (1996), $175-205$ 
[8] Heckman, James J., Rodrigo Pinto, Azeem M. Shaik and Adam Yavitz, "Inference With Imperfect Randomization: The Case of the Perry Preschool Program" NBER Working Paper No 16935 (2011).

[9] Heckman, James J. and Yona Rubinstein, "The Importance of Noncognitive Skills: Lessons from the GED Testing Program" American Economic Review 91:2 (2001), 145-149.

[10] Heckman, James J., Jora Stixrud and Sergio Urzua, "The effect of cognitive and non-cognitive abilities on labor market outcomes and social behavior" Journal of Labor Economics 24:3 (2006), 411-482.

[11] Keane, Michael P. and Kenneth I. Wolpin, "The Career Decisions of Young Men" Journal of Political Economy 105:3 (1997), 473-522.

[12] Lefcourt, Herbert M., "Locus of Control: Current Trends in Theory and Research" (Hillsdale, New Jersey: Lawrence Erlbaum Associates, 1976).

[13] Lerner, Joshua, "Boulevard of Broken Dreams: Why Public Efforts to Boost Entrepreneurship and Venture Capital Have Failed - and What to Do About It" (Princeton, New Jersey: Princeton University Press, 2010).

[14] Macpherson, David A., "Self-employment and Married Women" Economic Letters 28:3 (1988), $281-284$.

[15] Mealli, Fabrizia and Stephen Pudney, "Occupational Pensions and Job Mobility in Britain: Estimation of a Random-Effects Competing Risks Model" Journal of Applied Econometrics $11: 3$ (1996), 293-320

[16] Rotter, Julian B., "Generalized expectancies for internal versus external control of reinforcements" Psychological Monographs: General and Applied 80:1 (1966), 1-28 
[17] Savelyev, Peter A., "Conscientiousness, Education and Longevity of High-Ability Individuals" SSRN Working Paper (2011), available at http://ssrn.com/abstract=1715942.

[18] Simpson, Wayne and Robert Sproule, "Econometric Analysis of Canadian Self-Employment Using SLID” Income and Labour Dynamics Working Paper No. 98-16 (1998).

[19] Van der Sluis, Justin, Mirjam van Praag and Wim Vijverberg, "Education and Entrepreneurship Selection and Performance: a Review of the Empirical Literature" Journal of Economic Surveys 22:5 (2008), 795-841. 


\section{ACKNOWLEDGMENTS}

I would like to thank for many useful comments and advices Luigi Zingales, Erik G. Hurst, Robert J. LaLonde, Susanne M. Schennach, Steven N. Kaplan, Adair Morse, Luigi Guiso, Margarita Tsoutsoura, James J. Heckman, the participants to the Lifecycle Dynamics and Labor Economics, Capital Theory and Industrial Organization Working Groups, and the Micro Lunch at Chicago and the participants to the Brownbag Seminar at Boston Fed. Jacob Bergmann Larsen provided excellent research assistance. All remaining errors are mine. Please send any comment to asoni@uchicago.edu. This research was conducted with restricted access to Bureau of Labor Statistics (BLS) data. The views expressed here do not necessarily reflect the views of the BLS. Financial support from the Jan Wallander and Tom Hedelius Foundation is gratefully acknowledged. 


\section{APPENDIX}

\section{A Tables}

\begin{tabular}{lrrr}
\hline \hline & All & Male & Female \\
\hline \hline Observations & 12,686 & 6,394 & 6,292 \\
& & & \\
College & $23.52 \%$ & $23.39 \%$ & $23.65 \%$ \\
Minorities & $19.33 \%$ & $19.49 \%$ & $19.16 \%$ \\
Married & $59.15 \%$ & $57.02 \%$ & $61.36 \%$ \\
& & & \\
Ever Owned a Business & $23.17 \%$ & $27.17 \%$ & $19.03 \%$ \\
Business Owner & $6.95 \%$ & $9.39 \%$ & $4.45 \%$ \\
\hline \hline
\end{tabular}

Table 1: Comparison between men and women. All percentages are calculated as averages of the period 1988-2004 to refer to an adult population. In 1988 the youngest individuals is 24 years of age and virtually all the sample is out of school and either employed, self-employed or non-employed 


\begin{tabular}{lrrrr}
\hline \hline Year & Individuals & Students & Employed & College \\
\hline \hline $\mathbf{1 9 8 0}$ & 5,697 & $40.53 \%$ & $44.74 \%$ & $1.71 \%$ \\
$\mathbf{1 9 9 2}$ & 4,526 & $2.10 \%$ & $84.04 \%$ & $22.97 \%$ \\
$\mathbf{2 0 0 4}$ & 3,860 & $0.98 \%$ & $81.69 \%$ & $25.51 \%$ \\
\hline \hline
\end{tabular}

Table 2: Evolution of sample over time. First column reports the number of individuals in the sample in different years. The second column contains the percentage of people who are students in the sample, while the third and fourth the percentage who are employed and have a college degree. The entire sample contains about 90,000 man-year observations. 


\begin{tabular}{lrrr}
\hline \hline Year & Minorities & Intelligence & Self-confidence \\
\hline \hline $\mathbf{1 9 8 0}$ & $17.97 \%$ & $99.2(0.22)$ & $8.41(0.03)$ \\
$\mathbf{1 9 9 2}$ & $18.96 \%$ & $98.8(0.24)$ & $8.41(0.03)$ \\
$\mathbf{2 0 0 4}$ & $19.17 \%$ & $99.3(0.27)$ & $8.45(0.04)$ \\
\hline \hline
\end{tabular}

Table 3: Survivorship Bias. Standar Error in Parenthesis. First column reports the percentage of the population who is either African-American or Hispanic. Second column shows the average IQ in the sample as measured by the AFQT over time. The third column shows the average value of the Rotter's test for locus of control. Intelligence and self-confidence are not statistically different over time. 


\begin{tabular}{lrrr}
\hline \hline & Entrepreneurship & Wage workers & Non-employment \\
\hline \hline All & $8.7 \%$ & $77.4 \%$ & $14.0 \%$ \\
College & & & \\
No College & $8.0 \%$ & $86.7 \%$ & $5.4 \%$ \\
& $8.9 \%$ & $74.5 \%$ & $16.6 \%$ \\
High Intelligence & & & \\
Low Intelligence & $9.0 \%$ & $82.4 \%$ & $8.6 \%$ \\
& $6.5 \%$ & $65.7 \%$ & $27.9 \%$ \\
High Confidence & & & \\
Low Confidence & $10.4 \%$ & $76.9 \%$ & $12.7 \%$ \\
\hline \hline
\end{tabular}

Table 4: Employment Status. First column reports the percentage of the population who is selfemployed; the second column reports the share of people who work for someone else and the third column reports the percentage of the population who is either unemployed or out of the labor force. These numbers are calculated as averages over the years 1988-2004. In 1988 virtually all the people are out of school and are in one of the three categories. "College" refers to those with a 4-years college degree. "High Intelligence" are those who score on the AFQT test one standard deviation above the mean or higher. "Low Intelligence" are those who score one standard deviation below the mean or lower. "High Confidence" are those who score in the Rotter's Test for the locus of control one standard deviation lower than the mean or less. "Low Confidence" are those who score one standard deviation higher than the mean or more. 


\begin{tabular}{lrr}
\hline \hline & College & No College \\
\hline \hline High Intelligence & $8.2 \%$ & $9.9 \%$ \\
Low Intelligence & $2.9 \%$ & $6.5 \%$ \\
& & \\
High Confidence & $8.7 \%$ & $11.0 \%$ \\
Low Confidence & $5.0 \%$ & $7.3 \%$ \\
\hline \hline
\end{tabular}

Table 5: Entrepreneurs and college. Share of entrepreneurs among those with college education (column one) and those without (column two) by intelligence and confidence. 


\begin{tabular}{lrr}
\hline \hline & High Intelligence & Low Intelligence \\
\hline \hline High Confidence & $10.5 \%$ & $7.4 \%$ \\
Low Confidence & $6.1 \%$ & $6.5 \%$ \\
\hline \hline
\end{tabular}

Table 6: Entrepreneurs and intelligence. Share of entrepreneurs among people with high intelligence (column one) and low intelligence (column two) by confidence level. 


\begin{tabular}{llcll}
\hline \hline & \multicolumn{1}{c}{$\boldsymbol{I}$} & $\boldsymbol{I I}$ & $\boldsymbol{I I I}$ & \multicolumn{1}{c}{$\boldsymbol{I V}$} \\
\hline \hline College & 0.001 & & & -0.006 \\
& $(0.004)$ & & & $(0.004)^{*}$ \\
Intelligence & & 0.016 & & 0.017 \\
& & $(0.005)^{* * *}$ & & $(0.002)^{* * *}$ \\
Self-Confidence & & & -0.002 & -0.002 \\
& & & $(0.001)^{* * *}$ & $(0.001)^{* * *}$ \\
\hline \hline
\end{tabular}

Table 7: Human Capital and the Rate of Entrepreneurship. Standard errors in parenthesis. This table reports the marginal effects at the mean of the variables on the leftmost column on the probability of being entrepreneur derived from probit analysis. Each regression also controls for marital status, number of kids, race, deviations of local unemployment rate from mean, age, age squared and industry. In additional specifications I also controlled for family wealth and results do not change. Standard errors are clustered at the individual level. 


\begin{tabular}{|c|c|c|c|c|}
\hline & $I$ & II & III & $I V$ \\
\hline \multicolumn{5}{|c|}{ "Effect on Unincorporated Businesses } \\
\hline College & $\begin{array}{c}-0.004 \\
(0.003)\end{array}$ & & & $\begin{array}{l}-0.009 \\
(0.003) * * *\end{array}$ \\
\hline Intelligence & & $\begin{array}{l}0.009 \\
(0.005)^{* * *}\end{array}$ & & $\begin{array}{l}0.013 \\
(0.005)^{* * *}\end{array}$ \\
\hline Self-Confidence & & & $\begin{array}{l}-0.002 \\
(0.001)^{* * *}\end{array}$ & $\begin{array}{l}-0.002 \\
(0.001)^{* * *}\end{array}$ \\
\hline \multicolumn{5}{|c|}{ Effect on Incorporated Businesses } \\
\hline College & $\begin{array}{l}0.004 \\
(0.002)^{* *}\end{array}$ & & & $\begin{array}{l}0.003 \\
(0.001)^{*}\end{array}$ \\
\hline Intelligence & & $\begin{array}{l}0.005 \\
(0.001)^{* * *}\end{array}$ & & $\begin{array}{l}0.003 \\
(0.001)^{* *}\end{array}$ \\
\hline Self-Confidence & & & $\begin{array}{l}-0.001 \\
(0.000)^{* * *}\end{array}$ & $\begin{array}{l}-0.001 \\
(0.000) * * *\end{array}$ \\
\hline
\end{tabular}

Table 8: Human Capital and the Rate of Entrepreneurship, by business type. Standard errors in parenthesis. This table reports the marginal effects at the mean of the variables on the leftmost column on the probability of being entrepreneur derived from probit analysis. Each regression also controls for marital status, number of kids, race, deviations of local unemployment rate from the mean, age, age squared and industry. In additional specifications I also controlled for family wealth and the results do not change. Standard errors are clustered at the individual level. 


\begin{tabular}{|c|c|c|c|c|}
\hline & Entry Rate & \% from Employ. & $\%$ of Incorp. & Firms \\
\hline All & $2.6 \%$ & $66.7 \%$ & & $18.9 \%$ \\
\hline College & $2.5 \%$ & $70.4 \%$ & & $31.0 \%$ \\
\hline No College & $2.7 \%$ & $65.9 \%$ & & $16.3 \%$ \\
\hline High Intelligence & $2.5 \%$ & $70.9 \%$ & & $21.1 \%$ \\
\hline Low Intelligence & $2.1 \%$ & $56.3 \%$ & & $10.0 \%$ \\
\hline High Confidence & $2.8 \%$ & $65.9 \%$ & & $22.5 \%$ \\
\hline Low Confidence & $2.3 \%$ & $68.0 \%$ & & $18.0 \%$ \\
\hline
\end{tabular}

Table 9: Entry Rates. Entry rate is measured as the percentage of individuals who were not entrepreneurs during the previous year that became entrepreneur the current year. The value shown is an average of the period 1980-2004. The second column contains the percentage of firms that were created by people leaving a salaried job. The third column contains the percentage of firms created that are incorporated. 


\begin{tabular}{lrrr}
\hline \hline & Survival Rate & Surv. Rate - Incor. & Surv. Rate - Unincor. \\
\hline \hline All & $39.9 \%$ & $56.8 \%$ & $35.8 \%$ \\
College & & & \\
No College & $50.1 \%$ & $57.0 \%$ & $46.8 \%$ \\
& $37.9 \%$ & $56.7 \%$ & $34.1 \%$ \\
High Intelligence & & & \\
Low Intelligence & $49.1 \%$ & $59.6 \%$ & $45.6 \%$ \\
& $36.6 \%$ & $53.2 \%$ & $34.3 \%$ \\
High Confidence & & & $38.2 \%$ \\
Low Confidence & $43.5 \%$ & $62.8 \%$ & $36.9 \%$ \\
\hline \hline
\end{tabular}

Table 10: Survival Rates. Survival rate is measured as the percentage of firms still in business three years after their creation. First column shows it for all firms, the second and third distinguish between incorporated and unincorporated firms 


\begin{tabular}{|c|c|c|c|c|c|c|c|}
\hline & $I$ & II & III & $I V$ & $\boldsymbol{V}$ & VI & VII \\
\hline \multicolumn{8}{|c|}{ Entry from Employment } \\
\hline \multirow[t]{2}{*}{ College } & -0.119 & & & 0.005 & -0.041 & -0.212 & -0.090 \\
\hline & $(0.22)$ & & & $(0.96)$ & $(0.69)$ & $(0.13)$ & $(0.57)$ \\
\hline \multirow[t]{2}{*}{ Intelligence } & & -1.533 & & -1.582 & -0.734 & -2.163 & -2.299 \\
\hline & & $(0.00)^{* * *}$ & & $(0.00)^{* * *}$ & $(0.02)^{* *}$ & $(0.00)^{* * *}$ & $(0.00)^{* * *}$ \\
\hline \multirow[t]{2}{*}{ Self-Confidence } & & & -1.395 & -1.429 & -1.230 & -1.496 & -0.516 \\
\hline & & & $(0.00)^{* * *}$ & $(0.00)^{* * *}$ & $(0.00)^{* * *}$ & $(0.00)^{* * *}$ & $(0.06)^{*}$ \\
\hline \multicolumn{8}{|c|}{ Entry from Non-employment } \\
\hline \multirow[t]{2}{*}{ College } & 1.116 & & & 1.331 & 0.796 & 0.813 & 1.931 \\
\hline & $(0.00)^{* * *}$ & & & $(0.00)^{* * *}$ & $(0.00)^{* * *}$ & $(0.00)^{* * *}$ & $(0.00)^{* * *}$ \\
\hline \multirow[t]{2}{*}{ Intelligence } & & -1.868 & & -2.548 & 0.679 & -0.280 & -0.880 \\
\hline & & $(0.00)^{* * *}$ & & $(0.00)^{* * *}$ & $(0.15)$ & $(0.57)$ & $(0.57)$ \\
\hline \multirow[t]{2}{*}{ Self-Confidence } & & & -3.087 & -2.974 & -1.766 & -2.115 & -2.212 \\
\hline & & & $(0.00)^{* * *}$ & $(0.00)^{* * *}$ & $(0.00)^{* * *}$ & $(0.00)^{* * *}$ & $(0.10)^{*}$ \\
\hline Firms & All & All & All & All & All & Unincorp. & Incorp. \\
\hline Model & No selec. & No selec. & No selec. & No selec. & Selec. & Selec. & Selec. \\
\hline
\end{tabular}

Table 11: Human Capital and Business Creation. P-value in parenthesis. This table reports the coefficients of the variables on the leftmost column from the competing risks occupational model. Each regression also controls for marital status, number of kids, race, deviations of local unemployment rate from the mean, age, age squared and industry. Columns I-IV report results without correcting for endogeneity while column $\mathrm{V}$ reports the coefficient obtained correcting for the endogeneity of college education and entrepreneurship. Column VI reports the result for unincorporated businesses when correcting for endogeneity while column VII contains similar results for incorporated firms. 


\begin{tabular}{|c|c|c|c|c|c|c|c|}
\hline & $I$ & II & III & $I V$ & $\boldsymbol{V}$ & VI & VII \\
\hline \multicolumn{8}{|c|}{ Exit to Employment } \\
\hline \multirow[t]{2}{*}{ College } & -0.086 & & & 0.035 & -0.091 & 0.007 & -0.424 \\
\hline & $(0.45)$ & & & $(0.78)$ & $(0.50)$ & $(0.96)$ & $(0.36)$ \\
\hline \multirow[t]{2}{*}{ Intelligence } & & $-0 . .973$ & & -1.020 & -0.062 & -0.231 & -0.780 \\
\hline & & $(0.01)^{* * *}$ & & $(0.02)^{* *}$ & $(0.88)$ & $(0.62)$ & $(0.67)$ \\
\hline \multirow[t]{2}{*}{ Self-Confidence } & & & 0.099 & 0.046 & 0.316 & 0.183 & 1.687 \\
\hline & & & $(0.72)$ & $(0.87)$ & $(0.27)$ & $(0.56)$ & $(0.08)^{*}$ \\
\hline \multicolumn{8}{|c|}{ Exit to Non-employment } \\
\hline \multirow[t]{2}{*}{ College } & -0.333 & & & 0.154 & -0.111 & 0.072 & 0.877 \\
\hline & $(0.04)^{* *}$ & & & $(0.38)$ & $(0.61)$ & $(0.72)$ & $(0.09)^{*}$ \\
\hline \multirow[t]{2}{*}{ Intelligence } & & -3.775 & & -3.936 & -1.940 & -2.590 & -5.820 \\
\hline & & $(0.00)^{* * *}$ & & $(0.00)^{* * *}$ & $(0.00)^{* * *}$ & $(0.00)^{* * *}$ & $(0.01)^{* * *}$ \\
\hline \multirow[t]{2}{*}{ Self-Confidence } & & & 0.510 & 0.353 & 0.766 & 0.678 & 1.303 \\
\hline & & & $(0.16)$ & $(0.34)$ & $(0.05)^{* *}$ & $(0.06)^{*}$ & $(0.41)$ \\
\hline Firms & All & All & All & All & All & Unincorp. & Incorp. \\
\hline Model & No selec. & No selec. & No selec. & No selec. & Selec. & Selec. & Selec. \\
\hline
\end{tabular}

Table 12: Human Capital and Business Survival. P-value in parenthesis. This table reports the coefficients of the variables on the leftmost column from the competing risks occupational model. Each regression also controls for marital status, number of kids, race, deviations of local unemployment rate from the mean, age, age squared and industry. Columns I-IV report results without correcting for endogeneity while column $\mathrm{V}$ reports the coefficient obtained correcting for the endogeneity of college education and entrepreneurship. Column VI reports the result for unincorporated businesses when correcting for endogeneity while column VII contains similar results for incorporated firms. 


\section{B Construction of Yearly Employment Status}

The discrete observation period is assumed to be a calendar year. Any construction of yearly employment and schooling status starting from weekly or monthly self-reported situation is somewhat arbitrary since an individual can be in several alternatives in a given year. There is no unequivocal solution to this problem. I followed the classification method proposed by Keane and Wolpin (1997) who used the same dataset to estimate a life-cycle model.

Every young man is assigned to one of four mutually exclusive states (employment, self-employment, non-employment or school) in the following hierarchical way. First I establish whether someone can be classified as employed, non-employed, self-employed or his/her status is missing for the year. a) Missing Values, Employed or Non-employed. If the weekly working status is missing for more than $2 / 3$ of the weeks in one year, then the yearly status is missing. When weekly status is available for more than two thirds of the weeks then an individual is considered working if he/she reports doing so for more than two thirds of the non-missing weeks and averages at least 20 hours of work per week. Otherwise the yearly status is coded as "non-employment" ${ }^{6}$ b) Self-Employed. If an individual reports working as self-employed for more than half of the working weeks then he/she is considered self-employed for the year.

Second, I establish whether someone classified as "Non-employed" is, in fact, in school. An individual is classified in school during the current calendar year if he/she is not already classified as employed or self-employed and one of the two following statements is true: a) he/she reports one more year of education the following calendar year and reports attending school at least during one month in the current calendar year; or b) he/she reports attending school for at least four months during current calendar year. The second part of this definition is meant to capture those individuals who spent most of their time in school but for whatever reason did not complete the $\operatorname{grade}^{7}$

\section{Notes}

\footnotetext{
${ }^{1}$ As suggested by a preliminary analysis that uses the Cox Proportional duration model.

${ }^{2}$ National Center for Health Statistics "Vital Statistics of the United States, 1982". Life Tables,
} 
Volume 2, Section 6, p. 6. Available at:

http://www.cdc.gov/nchs/data/lifetables/life82_2acc.pdf

${ }^{3}$ The difference between locus of control and self-efficacy can be easily understood with the use of an example. If a student believes that she will earn high marks if she studies ten hours a day, then she has an internal locus of control. However, if she also believes that she is not able to study that hard then she has a low self-efficacy.

${ }^{4}$ I aggregated weekly statuses into yearly statuses. See Appendix for details.

${ }^{5}$ There are of course exceptions, such as those people who sell for a profit their firm and "retire" for a while, enjoying their wealth.

${ }^{6}$ Keane and Wolpin (1997) do a similar exercise but construct their employment variables looking at only nine weeks during the year. They do so for computational reasons. I do not have the same limitations so my working status uses all the information/weeks available. Keane and Wolpin also do not consider summer quarters to avoid picking up students' summer jobs. I calculate the working status with and without summer weeks. The correlation across individuals between the two definitions ranges between .9 in 1979 and .97 in 2003.

${ }^{7}$ I decided to give priority to the employment information rather than the schooling attendance variable because the former seems to be more accurate. First, it is collected on a weekly basis rather than a monthly basis. Second, in order to be employed someone needs to work for more than 20 hours a week. Third, according to the rules of the NLSY79, it is enough to have attended school for just one day in order to be classified as in school for the entire month. 